\title{
ОЦЕНКА ТАКТИКИ ВРАЧА ПРИ ПЕРВОМ ОБРАЩЕНИИ ПАЦИЕНТОВ С ПИГМЕНТНЫМИ ОПУХОЛЯМИ КОЖИ
}

\section{ASSESSMENT OF THE DOCTOR'S \\ TACTICS AT THE FIRST ADMISSION \\ OF PATIENTS WITH SKIN PIGMENTAL TUMORS}

\section{O. Konopatskova Yu. Stanchina}

Summary. In recent years, there has been an increase in the number of pigmented skin tumors. Analysis of doctors'tactics in patients with such pathology will help to avoid possible mistakes and improve the situation of secondary prevention of melanoma of the skin. To determine the causes of neglect and errors of doctors with skin melanoma, the tactics at the pre-hospital stage were retrospectively studied in 3136 patients who were registered at an oncological dispensary in the Saratov region for the period from 1980 to 2019. A prospective similar analysis was carried out in a group of patients with pigmented skin nevi -250 people.

Results. The analysis made it possible to draw attention to organizational and tactical errors of polyclinic doctors. These include: lack of oncological alertness of first-contact doctors conducting an examination of the population; incomplete examination; superficial collection of anamnesis (without taking into account risk factors); violation of the principle of routing patients with suspected cancer; monitoring of pigmented skin formations in the presence of symptoms of their activation.

Conclusions. The analysis of preclinical diagnostics for pigmented skin tumors showed that, as before, there are a number of organizational and tactical errors of first-contact doctors. The focus on these errors will not only increase the oncological alertness of this category of doctors, but also adjust tactics in this category of patients, which ultimately serves as a secondary prevention of skin melanoma.

Keywords: melanoma; pigmented nevus; tactics of first-contact doctors; medical errors.

\author{
Конопацкова Ольга Михайловна \\ Д.м.н., профессор, ФГБОУ ВО «Саратовский ГМУ \\ им. В.И. Разумовского» Минздрава России, Саратов \\ o.konopatskova@mail.ru \\ Станчина Юлия Валериевна \\ Аспирант, ФГБОУ ВО «Саратовский ГМУ \\ им. В.И. Разумовского» Минздрава России, Саратов \\ juvfresh@yandex.ru
}

Аннотация. В последние годы отмечается увеличение числа опухолей кожи пигментного характера. Анализ тактики врачей у пациентов с подобной патологией поможет избежать возможных ошибок и улучшить ситуацию по вторичной профилактике меланомы кожи. Для определения причин запущенности и ошибок врачей при меланоме кожи ретроспективно изучена тактика на догоспитальном этапе у 3136 больных, находившихся на учете в онкологическом диспансере в Саратовской области за период с 1980 по 2019 гг. Проспективный аналогичный анализ проведен в группе пациентов с пигментными невусами кожи - 250 человек.

Результаты. Проведенный анализ позволил обратить внимание на организационные и тактические ошибки врачей поликлинического звена. К ним отнесены: отсутствие онконастороженности врачей первого контакта, проводящих осмотр населения; неполное обследование; поверхностный сбор анамнеза (без учета факторов риска); нарушение принципа маршрутизации больных с подозрением на онкозаболевание; наблюдение за пигментными образованиями кожи при наличии симптомов их активизации.

Выводы. Анализ доклинической диагностики при пигментных опухолях кожи показал, что, по-прежнему, имеется ряд организационных и тактических ошибок врачей первого контакта. Акцент на эти ошибки позволит не только повысить онкологическую настороженность данной категории врачей, но и скорректировать тактику у этой категории больных, что, в конечном итоге, служит вторичной профилактикой меланомы кожи.

Ключевые слова: меланома; пигментный невус; тактика врачей первого контакта; врачебные ошибки.

2011). В связи с высокой заболеваемостью, не теряет актуальность вопрос и о предмеланомной патологии кожи, в частности, о пигментных невусах и адекватной тактике при них в концепции вторичной профилактики меланомы [Ахматова А.М. с соавт., 2011; Малишевская Н.П., 2014]. Поэтому для врача, ведущего амбулаторный прием, обязательным условием эффективной работы является наличие онкологической насторо- 
женности и знание основных клинических признаков, позволяющих своевременно и правильно определить тактику при пигментных образованиях.

\section{Це^ь}

Проанализировать тактику врачей на этапе первого обращения пациентов, имеющих пигментные опухоли кожи.

\section{Материалы и метолы}

С целью определения причин запущенности и ошибок врачей, ретроспективно изучена тактика на догоспитальном этапе у 3136 больных меланомой в Саратовской области в 1980-2019гг. Меланома чаще встречалась в возрасте старше 60 лет (1772 человека - 56,5\%). У основной массы больных (2984-95,2\%) фоном для развития меланомы послужили пигментные невусы, как приобретенные (2520 пациентов - 80,4\%), так и врожденные (464 человек - 14,8\%). Меланома, развивающаяся на фоне врожденного пигментного невуса, чаще наблюдалась в возрасте до 39 лет - 441 человек (86,3\%); на фоне приобретенного пигментного невуса - у лиц старше 40 лет - 2467 больных (97,9\%). Появление меланомы на неизмененной коже - в группе лиц старше 40 лет - 70 человек (89,7\%). Проспективную группу составили 250 пациентов с клинически установленным диагнозом пигментного невуса кожи. Среди них преобладали женщины 170 (68\%), имеющие II-III фототип кожи - 232 (92,8\%); узловую форму роста невуса - (134-65,2\%) и гистологически - внутридермальный тип (171 пациент - 61,2\%).

\section{Результаты}

По результатам ретроспективного анализа удалось уточнить время, прошедшее от начала появления изменений до первого обращения к врачу. У большинства больных этот период составлял от одного месяца до года (1912 пациентов - 61\%). Непосредственно после появления каких-либо жалоб к врачу обратились 155 человек (4,9\%); в период от года до пяти лет - 1069 больных (34,1\%). Основная жалоба, с которой обращались к врачу, была на быстрый темп роста (как правило, в течение 6 месяцев) предшествующего пигментного образования. Это отметили 1975 человек (63\%). Другими жалобами были изменение поверхности (775 пациентов - 24,7\%) и цвета (386 человек - 12,3\%). Из анамнеза определяли причины, способствующие активизации: солнечная инсоляция у 1938 (61,8\%) человек; хроническая травматизация предшествующего пигментного образования у 926 (29,5\%); изменения, связанные с гормональным воздействием - у 231 $(7,4 \%)$ пациентов. Не выяснены причины у $41(1,3 \%)$ че- ловек. Проведенный ретроспективный анализ качества диагностики меланомы на первом этапе показал, что с момента первого обращения к врачу до начала лечения только у 907 (28,9\%) человек из 3136 была избрана правильная тактика: пациенты сразу были консультированы онкологом и направлены на лечение. Длительное наблюдение (более шести месяцев) по рекомендации врача (при наличии симптомов активизации), отсутствие консультации онколога и морфологической верификации отмечено у 2073 (66,1\%) пациентов. Не проявилась онкологическая настороженность при осмотре 156 (5\%) человек, которые были отпущены домой без дальнейших рекомендаций, т.к. имеющаяся патология, по мнению врача первого контакта, не представляла опасности.

Для изучения тактики ведения на амбулаторном этапе проанализированы медицинские карты 250 человек, имеющих пигментные невуса (впоследствии подтвержденные гистологически). Из анамнеза установлено, что у 196 (78,4\%) человек невус был приобретенным, у 54 $(21,6 \%)$ - врожденным. Это соотношение было, практически, одинаковым у женщин и мужчин. Поводом для обращения к врачу, чаще всего, служил рост невуса у 88 (35,2\%) пациентов. Изменение цвета в сторону гиперпигментации отметили 53 (21,2\%) человека, изменение поверхности (неравномерность, шелушение) - 41 $(16,4 \%)$, зуд, жжение - 39 (15,6\%) человек. В анамнезе у $86(34,4 \%)$ пациентов отмечена неоднократная травма невуса. Реже обращали внимание на нечеткость контуров - 20 (8\%); у 9 (3,6\%) пациентов жалоб не было и обратились они к врачу с целью удаления по косметическим соображениям. После появления беспокоящих признаков сразу к врачу обратились 63 (25,2\%) человека, но чаще пациенты обращались за медицинской помощью в течение двух-шести месяцев с момента появления изменений пигментного невуса - 127 (50,8\%) человек. На дополнительную консультацию к онкологу были направлены 70 (28\%) пациентов из 250 и им сразу была дана рекомендация удаления в диспансере. Наблюдались врачами в поликлинике без проведения консультации онколога 148 (59,2\%) человек: у хирурга - 59 (39,9\%), у дерматолога $89(60,1 \%)$ пациентов. Непосредственно онколог наблюдал 32 (12,8\%) человека. Сроки наблюдения: месяц 39 (21,7\%), до трех месяцев 67 (37,2\%), до шести месяцев - 43 (23,9\%), более полугода - 31 пациент $(17,2 \%)$.

Таким образом, при определении причин запущенности и ошибок врачей, проведенный анализ на догоспитальном этапе у 3136 больных меланомой показал, что от начала появления признаков, беспокоящих пациентов до обращения к врачу у 1912 человек (61\%) прошло от месяца до года. Тактика врачей поликлинического звена не всегда была адекватной: длительное 
наблюдение за больными, даже при наличии симптома роста, констатировано у 2073 (66,1\%) человек. Качество оказываемой медицинской помощи, а именно недостаточная онконастороженность врачей первого контакта, формализм приема и отсутствие наружного осмотра кожного покрова на наличие пигментных образований привели, естественно, к врачебным ошибкам. К ним отнесены: отсутствие онконастороженности врачей первого контакта, проводящих осмотр населения; неполное обследование; поверхностный сбор анамнеза (без учета факторов риска); нарушение принципа маршрутизации больных с подозрением на онкозаболевание; дефекты обследования (больных не всегда консультировал онколог); наблюдение при наличии симптомов активизации. До настоящего времени многие из врачей различных специальностей считают возможным самостоятельно решать тактические вопросы, не прибегая к консультации онколога. Естественно, что все это отрицательно сказывается на тактике. Представленные сведения свидетельствуют о низкой эффективности работы врачей первого контакта. Самой частой тактической ошибкой было длительное наблюдение за больными: при меланоме кожи у 2073 больных $(66,1 \%)$ из 3136; при пигментных невусах - 180 (72\%) пациентов из 250. Сразу были направлены в стационар 907 (28,9\%) из 3136 больных меланомой и 70 (28\%) из 250 пациентов с невусами. Остальных наблюдали в поликлинике в течение разного срока, как правило, те же врачи, к которым пациенты обратились в первый раз.

Таким образом, проведенный анализ врачебных ошибок доказывает необходимость перманентного обучения на информационных курсах врачей поликлинического звена (дерматолога, косметолога, хирурга), не имеющих специализации онкологов, с целью повышения онкологической настороженности в отношении диспластических пигментных невусов кожи, а также обосновывает применение в их повседневной практике как классических, так и новых неинвазивных способов диагностики пигментных опухолей кожи, определяющих лечебную тактику.

\section{Зак^ючение}

Для онкологов является давно доказанным тот факт, что пигментные образования на коже просто обнару- жить при физикальном осмотре, поэтому обязанностью врача любой специальности должно быть непременное обследование кожи. В этой ситуации нельзя говорить о слабом материально-техническом обеспечении медицинских учреждений, т.к. диагностические аппараты если и отсутствуют, то всегда есть возможность дополнительной консультации, а правомочность цитологической диагностики пигментных опухолей кожи не вызывает сомнений. Своевременное выявление и удаление диспластических пигментных невусов следует рассматривать как фактор вторичной профилактики меланомы кожи.

\section{Выво $\triangle$}

Анализ эффективности диагностики пигментных опухолей кожи на амбулаторно-полклиническом этапе оказания медицинской помощи показал, что, по-прежнему, имеется ряд организационных и тактических ошибок врачей первого контакта. Акцент на эти ошибки позволит не только повысить онкологическую настороженность врачей, не имеющих квалификации онкологов, но и, своевременно скорректировать тактику у этой категории больных.

\section{Аополните^ьная информачия}

Конфликт интересов. Авторы декларируют отсутствие явных и потенциальных конфликтов интересов, о которых необходимо сообщить в связи с публикацией данной статьи.

Этика. Проведенное исследование одобрено комитетом по этике ФГБОУ ВО Саратовского государственного медицинского университета им. В.И. Разумовского Минздрава России по протоколу № 9 от 7 мая 2019года. В исследовании использованы данные людей в соответствии с подписанным информированным согласием.

Финансирование. Исследование не имело спонсорской поддержки

Участие авторов. Концепция, дизайн исследования, редактирование - Конопацкова О.М. Сбор материала, написание текста статьи - Станчина Ю.В.

\section{ЛИТЕРАТУРА}

1. WHO. Ultraviolet radiation and the INTERSUN Programme [Electronic resource]. URL: http://www.who.int/uv/faq/skincancer/en/index1.html (Access Aug 2013).

2. Анализ пятилетней выживаемости больных с меланомой по данным Федерального ракового регистра / Г.В. Петрова, О.П. Грецова, Ю.И. Простов, М.Ю. Простов // Онкология. Журнал им. П.А. Герцена. 2014. № 3. С. 47-50.

3. Гельфонд М.Л. Дифференциальная диагностика опухолей кожи в практике дерматологов и косметологов // Практическая онкология. 2012. Т. 13, № 2. C. $69-79$ 
4. Malignant Melanoma in the $21^{\text {st }}$ Century, Part 1: Epidemiology, Risk Factors, Screening, Prevention, and Diagnosis / S.N. Markovic, L.A. Erickson, R.D. Rao [et al.] // Mayo Clin. Proc. 2007. Vol. 82, № 3. P. 364-380.

5. Whiteman D.C., Pavan W.J., Bastian B.C. The melanomas: a synthesis of epidemiological, clinical, histopathological, genetic, and biological aspects, supporting distinct subtypes, causal pathways, and cells of origin // Pigment cell \& melanoma research. 2011. Vol. 24, № 5. P. 879-897.

6. Ахматова А.М., Потекаев Н.Н., Решетов И.В., и др. Кпроблеме ранней диагностики меланомы кожи// Клиническая дерматология и венерология. 2011. № 2. C. 4-6

7. Малишевская Н.П., Соколова А.В. Современные методы неинвазивной диагностики меланомы кожи // Вестник дерматологии и венерологии. 2014. № 4. C. 46-53.

( Конопацкова Ольга Михайловна ( o.konopatskova@mail.ru ), Станчина Юлия Валериевна ( juvfresh@yandex.ru ).

Журнал «Современная наука: актуальные проблемы теории и практики»

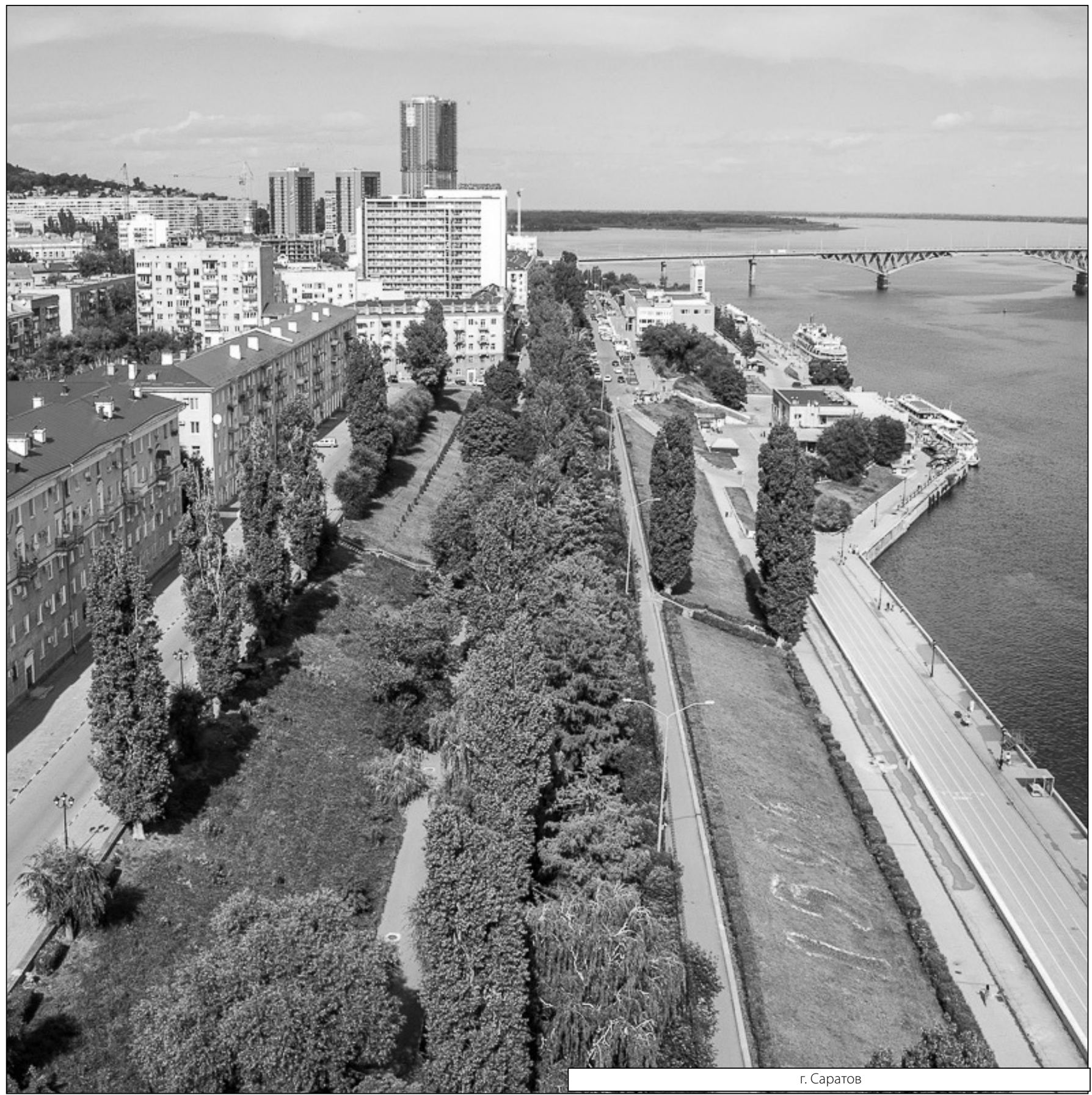

